\title{
Biochemical endpoints on juvenile Solea senegalensis exposed to estuarine sediments: the effect of contaminant mixtures on metallothionein and CYP1A induction
}

\author{
Pedro M. Costa $\cdot$ Sandra Caeiro $\cdot$ Mário S. Diniz $\cdot$ Jorge Lobo $\cdot$ \\ Marta Martins · Ana M. Ferreira • Miguel Caetano · Carlos Vale • \\ T. Ángel DelValls $\cdot$ Maria H. Costa
}

Accepted: 24 June 2009/Published online: 15 July 2009

(C) Springer Science+Business Media, LLC 2009

\begin{abstract}
Juvenile Solea senegalensis were exposed to fresh sediments from three stations of the Sado estuary (Portugal) in 28-day laboratory assays. Sediments revealed distinct levels of total organic matter, fine fraction, redox potential, trace elements (arsenic, cadmium, chromium, copper, nickel, lead and zinc) and organic contaminants (polycyclic aromatic hydrocarbons, polychlorinated biphenyls and a pesticide: dichloro diphenyl trichloroethane). Organisms were surveyed for contaminant bioaccumulation and induction of two hepatic biochemical biomarkers: metallothionein (MT) and cytochrome P450 (CYP1A), as potential indicators of exposure to metallic
\end{abstract}

P. M. Costa $(\bowtie) \cdot$ S. Caeiro · M. S. Diniz · J. Lobo ·

M. H. Costa

IMAR-Instituto do Mar, Departamento de Ciências e Engenharia

do Ambiente, Faculdade de Ciências e Tecnologia da

Universidade Nova de Lisboa, 2829-516 Caparica, Portugal

e-mail: pmcosta@fct.unl.pt

S. Caeiro

Departamento de Ciências Exactas e Tecnológicas, Universidade Aberta, Rua da Escola Politécnica, 141, 1269-001 Lisbon, Portugal

M. S. Diniz

REQUIMTE, Centro de Química Fina e Biotecnologia, Departamento de Química, Faculdade de Ciências e Tecnologia da Universidade Nova de Lisboa, 2829-516 Caparica, Portugal

M. Martins - A. M. Ferreira - M. Caetano - C. Vale IPIMAR-INRB, Instituto Nacional dos Recursos Biológicos, Avenida de Brasília, 1449-006 Lisbon, Portugal

T. Á. DelValls

UNESCO/UNITWIN/WiCop Chair-Departamento de Química

Física, Facultad de Ciencias del Mar y Ambientales,

Universidad de Cádiz, Polígono río San Pedro s/n,

11510 Puerto Real, Cadiz, Spain and organic contaminants, respectively. Using an integrative approach it was established that, although bioaccumulation is in general accordance with sediment contamination, lethality and biomarker responses are not linearly dependent of the cumulative concentrations of sediment contaminants but rather of their bioavailability and synergistic effects in organisms. It is concluded that metals and organic contaminants modulate both MT and CYP1A induction and it is suggested that reactive oxygen species may be the link between responses and effects of toxicity.

Keywords Senegalese sole - Contaminated sediments . Bioaccumulation · Metallothionein $\cdot$ CYP1A $\cdot$ Sado estuary

\section{Introduction}

Ecological risk assessment of aquatic sediments has many constraints related to the difficulty in determining causeeffect relationships when toxicity results from mixtures of contaminants and the sediment characteristics that determine their bioavailability (Chapman 1990). Although laboratory and in situ tests using a wide range of aquatic organisms have proven its usefulness to assess the ecological risk of dredged materials and natural-state sediments, much research is still in need to fully understand the effects and implications of the toxicity of such a complex media. Also, even though benthic fish such as the Senegalese sole, Solea senegalensis Kaup, 1858 (Pleuronectiformes: Soleidae), have been successfully employed in bioassays with contaminated sediments (Jiménez-Tenorio et al. 2007; Costa et al. 2008a), little research has been able to relate toxicity effects and responses to specific classes of mixed sediment contaminants or their interactions. 
Metallothionein or metallothionein-like proteins (MTs) are small cytosolic heat-resistant proteins $(\approx 6-7 \mathrm{kDa})$ formed by two globular subunits, each comprising a high content (about 20) of free thiolic (-SH) groups from cysteine residues that are able to sequester metallic ions. The structure of these ubiquitous, highly conserved, proteins is linked to their role in the homeostasis of essential metals such as zinc $(\mathrm{Zn})$ and copper $(\mathrm{Cu})$ and detoxification of toxic elements such as cadmium $(\mathrm{Cd})$ and mercury $(\mathrm{Hg})$. For these reasons, gene overexpression (induction) of MTs has long been proposed as a biomarker of metal exposure, since metallic ions are capable of activating a metal response transcription factor (MTF) which will promote MT gene transcription by binding to specific DNA sites. MTs have several isoforms, apparently induced by different metals, the best known of which (MT-I and MT-II) are greatly induced by $\mathrm{Cd}$ and Zn (reviewed by Viarengo et al. 1999; Romero-Isart and Vašak 2002).

Cytochrome P4501A (CYP1A) consists of a membrane enzymatic system of monooxygenases involved in the catabolism of organic toxic xenobiotics such as polychlorinated biphenyls (PCBs) and polycyclic aromatic hydrocarbons (PAHs). These toxicants have the ability to induce CYP1A gene transcription by binding to a specific receptor, the aryl hydrocarbon receptor (AhR). Determination of CYP1A protein content or activity has been widely used as biomarker of exposure to organic contaminants in a broad range of organisms. An important characteristic of CYP1A catalytic activity is the formation of highly toxic (but more soluble, thus more easily excretable) intermediate products (many of which are strongly genotoxic) and reactive oxygen species (ROS); substances that are responsible for a diffuse and non-specific toxicity (see Jönsson et al. 2009 for a recent review).

The Sado estuary is a large coastal area subjected to various anthropogenic pressures, from urbanistic to industrial (comprising one of the highest heavy-industry concentrations in Portugal) and also agriculture (at upstream grounds), aquaculture, tourism and fisheries. Part of the estuary is also classified as a natural reserve. The obvious conflict between anthropogenic exploitation and the need to preserve environmental quality ultimately determine the importance of implementing ecological risk assessment strategies.

The main goals of the present work consist of: (1) to assess chronic sediment toxicity to juvenile $S$. senegalensis through analysis of bioaccumulation and MT and CYP1A induction in the liver, typically considered as toxicity biomarkers for metals and organic compounds, respectively; (2) to integrate sediment parameters and contaminants with the effects and responses in fish to assess toxicant bioavailability and (3) to evaluate the effects and responses of sediment-based contaminant mixtures to the organisms.

\section{Materials and methods}

\section{Experimental design}

The three sites of the Sado estuary (Fig. 1) were chosen according to their distinct characteristics: site A (the reference location) is the closest to the Natural Reserve and the farthest from pollution sources and has the smallest water residence time, therefore being the least contaminated, whereas sites B and C, located off Setúbal's harbour and industrial belt, respectively, are potentially the most contaminated. Sediments were collected with a Petit Po$\operatorname{nar}^{\circledR}$ grab on November 2006 and were analyzed immediately for their redox potential (Eh), homogenized and subdivided into samples to be frozen for posterior analyses or to be used fresh in the assays. For simplification purposes, exposure to the three sediments is throughout referred to as tests $\mathrm{A}, \mathrm{B}$ and $\mathrm{C}$.

For each test, $2 \mathrm{~L}$ of sediment were placed in $15 \mathrm{~L}$ polyvinyl tanks (providing $\approx 525 \mathrm{~cm}^{2}$ of sediment surface) with $12 \mathrm{~L}$ of clean seawater and let settle for $48 \mathrm{~h}$ prior to the beginning of the assays. Assays were dynamic, with constant aeration, and performed in duplicate. Water flow was set to prevent hydrodynamic-driven sediment resuspension. A quarter of the total water volume was changed weekly in order to mimic and keep constant the animals'

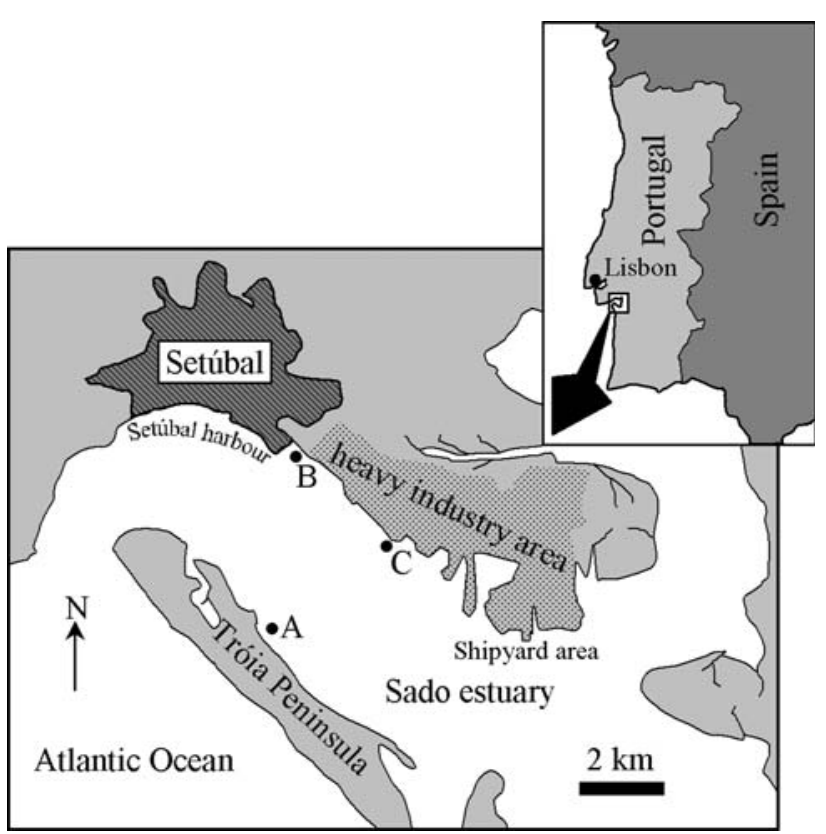

Fig. 1 Map of the Sado estuary showing the three sediment collection sites, $A, B$ and $C(\bullet)$ 
rearing conditions with minimal removal of suspended matter or waterborne contaminants. Measured parameters throughout the duration of the assays were: $\mathrm{pH}=7.9 \pm 0.2$, salinity $=33 \pm 1$, temperature $=18 \pm 1^{\circ} \mathrm{C}$, dissolved $\mathrm{O}_{2}$ $\left(\mathrm{DO}_{2}\right)$ ranged between 40 and $45 \%$ and total ammonia was restrained within $2-4 \mathrm{mg} \mathrm{L}^{-1}$. Photoperiod was set at 12:12 h light:dark. The water parameters were monitored weekly and simultaneously a water sample was taken for vacuum filtration with a GFC filter to determine the amount of suspended particulate matter.

Twenty-four juvenile hatchery-brood and laboratoryreared S. senegalensis [69 $\pm 6 \mathrm{~mm}$ standard length $\left.\left(L_{\mathrm{s}}\right)\right]$, all from the same cohort, were randomly distributed by each tank. Animals were fed daily with M2 grade commercial fish pellets (AQUASOJA) for the duration of the assay. Sampling times were scheduled for days $0\left(T_{0}\right), 14$ $\left(T_{14}\right)$ and $28\left(T_{28}\right)$. At sampling times $T_{14}$ and $T_{28} 12$ animals per exposure treatment (six per replica) were sacrificed, measured for $L_{\mathrm{s}}$ and total wet weight $\left(\mathrm{ww}_{\mathrm{t}}\right)$ and the liver was excised for biomarkers and metal bioaccumulation analyses. Remaining animals (up to six per replica, depending on mortality) were analysed for organic contaminant bioaccumulation. $T_{0}$ individuals consisted of 12 fish collected directly from the rearing tanks.

\section{Sediment characterization}

Sediments were characterized for total organic matter (TOM) by complete ignition at $500 \pm 50^{\circ} \mathrm{C}$. Fine fraction (FF, particle size $<63 \mu \mathrm{m}$ ) was determined by hydraulic sieving, as described by Caeiro et al. (2005). Both results are expressed as \% relatively to sediment dry weight (dw).

Sediment metallic elements were determined from dry samples mineralized in acid $(6 \mathrm{~mL} \mathrm{HF} 40 \% \mathrm{v} / \mathrm{v}$ to which was added $1 \mathrm{~mL}$ of the mixture $36 \% \mathrm{HCl}$ plus $60 \% \mathrm{HNO}_{3}$ $3: 1 \mathrm{v} / \mathrm{v}$ ) in closed Teflon vials (Caetano et al. 2007). Arsenic (As), cadmium $(\mathrm{Cd})$, chromium $(\mathrm{Cr})$, copper $(\mathrm{Cu})$, nickel $(\mathrm{Ni})$, lead $(\mathrm{Pb})$ and zinc $(\mathrm{Zn})$ were quantified by inductively coupled plasma mass spectrometry (ICP-MS). MESS-2 (NRC, Canada), PACS-2 (NRC, Canada) and MAG-1 (USGS, USA) reference sediments were analyzed to validate the procedure and the obtained metal concentrations were found within the certified range.

Sediment PAHs were analyzed from dry samples spiked with surrogate standards (SUPELCO), Soxhlet-extracted with an acetone + hexane $(1: 1 \mathrm{v} / \mathrm{v})$ mixture and quantified by gas chromatography-mass spectrometry (GC-MS) as described by Martins et al. (2008). Seventeen 3- to 6-ring PAHs were quantified, with total PAHs (tPAH) meaning the sum of all individual PAHs. PCBs (18 congeners) and DDTs ( $\mathrm{pp}^{\prime}$ DDT plus the metabolites $\mathrm{pp}^{\prime} \mathrm{DDD}$ and $\mathrm{pp}^{\prime} \mathrm{DDE}$ ) were quantified from dried sediment samples Soxhletextracted with $n$-hexane, fractioned in a chromatographic column and quantified by GC-MS (Ferreira et al. 2003). tPCB and tDDT represent the sum of the concentration of all analyzed PCB congeners and DDTs, respectively. Validation of the procedure was obtained by analysis of the SRM 1941b reference sediment (NIST, USA) and the concentrations of surveyed organic compounds were found within the certified range.

\section{Bioaccumulation}

Metal bioaccumulation was determined from vacuum-dried $(24 \mathrm{~h})$ liver samples from each individual, digested in Teflon vials with $\mathrm{HNO}_{3}$ and $\mathrm{H}_{2} \mathrm{O}_{2}$, according to Clesceri et al. (1999). The concentrations of a metalloid (As) and six metals $(\mathrm{Cd}, \mathrm{Cr}, \mathrm{Cu}, \mathrm{Ni}, \mathrm{Pb}$ and $\mathrm{Zn})$ were determined by ICP-MS. DORM2 and DOLT3 reference materials (NRC, Canada) were used to validate analysis and the obtained values were found within the certified range. In order to ensure enough biomass to survey PAHs, PCBs and DDTs (a minimum of $\approx 5 \mathrm{~g}$ per Soxhlet extraction was required), organic contaminants were quantified in wet muscle samples pooled from up to 12 fish. Quantification was performed similarly to the procedure described in the previous section, adapted to biological tissue by Martins et al. (2008). Validation was obtained by analysis of reference mussel tissue SRM 2977 (NIST, USA) and values were found to be within the certified range.

\section{Biomarker analyses}

Metallothionein induction was assessed by quantification of thiols in individual heat-treated liver cytosols $\left(80^{\circ} \mathrm{C}\right.$, $10 \mathrm{~min}$ ) extracted in Tris-HCl $0.02 \mathrm{M}$ buffer ( $\mathrm{pH}$ 8.6), by differential pulse polarography with a static mercury drop electrode (DPP-SMDE), as described by Costa et al. (2008b). In absence of an available commercial fish MT, rabbit MT (forms I \& II) from SIGMA was used for standard addition. The presence of a MT-compatible protein in liver cytosols was verified by sodium dodecyl sulphate-polyacrylamide gel electrophoresis (SDS-PAGE), through comparison of cytosolic protein migration distances with rabbit MT and the Pre-Stained Broad-Range rotein ladder (BIO-RAD) using the software Quantity One (BIO-RAD). Due to difficulties in SDS-PAGE visualization of MTs, a specific method described by Costa and Costa (2008) was employed, using a 19\% acrylamide/ bis-acrylamide running gel, and gels were stained by the blue-silver method with coomassie brilliant blue G250 (Candiano et al. 2004).

CYP1A induction was determined from pooled liver samples (of 12 individuals) for each test and sampling time, in order to have sufficient tissue mass for analysis (50-100 mg). Quantification was assessed by 
enzyme-linked immunosorbent assay (ELISA) in the microssomal fraction of liver homogenates, according to Nilsen et al. (1998) using a polyclonal antibody (CP226) against fish CYP1A (BIOSENSE). CYP1A extraction and quantification was performed in triplicate to determine the error of procedure. In absence of a commercial fish CYP1A standard, results are given in $\%$ of CYP1A induction over $T_{0}$.

\section{Statistical analyses}

Correlation-based principal component analysis (PCA) was employed to discriminate the most relevant variables explaining the variance between tested fish. A multivariate approach to integrate all biological data, namely fish size, bioaccumulation and biomarkers was performed through generalized linear models (GLM) in order to create a MT induction model based on biological parameters. The model was fitted through a Gamma regression (bioaccumulation + CYP1A induction $+\mathrm{ww}_{\mathrm{t}} \times L_{\mathrm{s}}$ interaction) with an identity link. Statistical inference on explanatory variables (model components) was obtained by ANOVA based on the reduction of deviance by sequential variable addition. Inference on coefficients was done by the Student's $t$-test. The model was validated by the criteria of randomness of Pearson (standardized) residuals $\times$ fitted values, normality of Pearson residuals and Cook's statistic $h$ for assessment of individual case biasing on model estimates. Observed $\times$ predicted chi-square tests were used to assess differences between sampling times of sediment contaminants and organic compound bioaccumulation. Non-parametric statistics (Kruskall-Wallis $H$, Mann-Whitney $U$ and Spearman's rank-order correlation $R$ ) were employed whenever the Levene's and Kolmogoroff-Smirfnoff's tests failed to demonstrate the homogeneity of variances or normality of data assumptions, respectively. GLM analysis was performed with the software $R$ (Ihaka and Gentleman 1996), all other statistics were computed with Statistica (STATSOFT), following McCullagh and Nelder (1989) and Sheskin (2000), respectively.

\section{Results}

The three tests yielded very distinct mortalities at the end of the assays: test $\mathrm{C}$ was responsible for the highest lethality (48\%), followed by B (12\%) and A (2\%). Growth at the end of the experiment was not found significant when compared to $T_{0}$ and also between tests and replicates (Kruskall-Wallis $H, P>0.05$ ). Average $L_{\mathrm{s}}$ and $\mathrm{ww}_{\mathrm{t}}$ at the end of each sampling time were $70 \pm 6 \mathrm{~mm}$ and $4.21 \pm 1.53 \mathrm{~g}$, respectively.

\section{Sediment characterization}

Burying and scavenging activities of the animals were observed to cause a strong resuspension of the sediments that progressively decreased during the assays, most likely due to the periodical water changes and to the dynamic structure of the assays, leading to a decrease in suspended particulate matter (Fig. 2).

Sediments from the three sites revealed distinct characteristics and contamination patterns (Table 1). Sediment $C$ was found to be the most anoxic and $\mathrm{B}$ with the highest TOM and FF percentages. As expected, sediment $\mathrm{A}$ is the overall least contaminated, while $\mathrm{B}$ is the most contaminated by metals. A comparison between the measured contaminant concentrations and available sediment quality guidelines (SQGs), namely the threshold effects level (TEL) and the probable effects level (PEL) confirmed sediment A to be the least contaminated, with sediments $\mathrm{B}$ and $\mathrm{C}$ being moderately contaminated, the first reaching PEL thresholds for $\mathrm{Cu}$ and $\mathrm{Zn}$. Four- and five-ring PAHs were the best represented organic toxicants, with perylene in sediment $\mathrm{C}$ reaching much higher levels (more than twofold) than in $\mathrm{B}$. The phenanthrene/anthracene and fluoranthene/pyrene ratios were $>1$ and $<10$, respectively, for all sediments, indicating the essentially pyrolytic (combustion-derived) origin of PAHs. PCBs were consistently more concentrated in sediment $\mathrm{C}$ when compared to $\mathrm{A}$ and $\mathrm{B}$. DDT (and its metabolites) was the least represented organic contaminant, presenting higher levels in sediment B.

\section{Bioaccumulation}

Metal bioaccumulation in the liver was in general low for all tests but more evident at $T_{14}$, especially for test B (Fig. 3a-g). Bioaccumulation was most notorious for As, $\mathrm{Cr}$ and $\mathrm{Zn}$. Lead accumulation was found to be the most

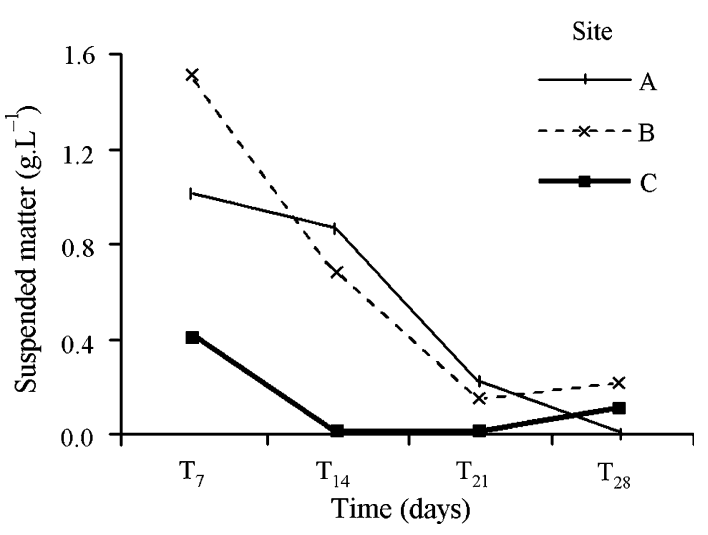

Fig. 2 Time-point measurements of total suspended matter (at $T_{7}$, $T_{14}, T_{21}$ and $T_{28}$ ). Points are connected to illustrate the evolution of suspended particles throughout the assays 
Table 1 Characterization of tested sediments and comparison of contaminant levels to available TEL and PEL SQGs, given in mg kg ${ }^{-1}$ sediment $\mathrm{dw}$ for metals and $\mu \mathrm{g} \mathrm{kg}^{-1}$ sediment $\mathrm{dw}$ for organic substances (from MacDonald et al. 1996)

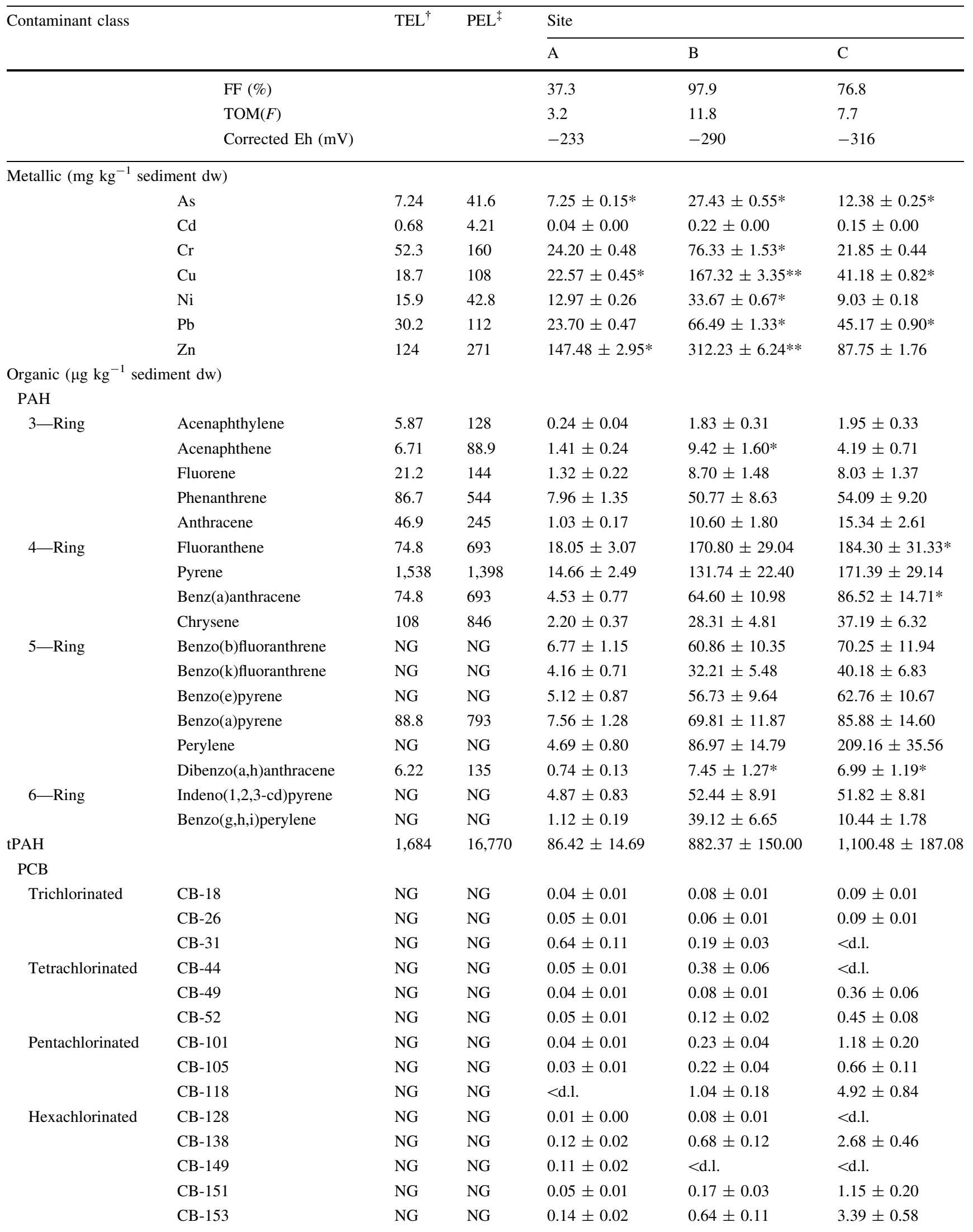


Table 1 continued

\begin{tabular}{|c|c|c|c|c|c|c|}
\hline \multirow[t]{2}{*}{ Contaminant class } & & \multirow[t]{2}{*}{$\mathrm{TEL}^{\dagger}$} & \multirow[t]{2}{*}{$\mathrm{PEL}^{*}$} & \multicolumn{3}{|l|}{ Site } \\
\hline & & & & A & B & $\mathrm{C}$ \\
\hline \multirow[t]{4}{*}{ Heptachlorinated } & CB-170 & NG & NG & $0.07 \pm 0.01$ & $0.27 \pm 0.05$ & $<$ d.1. \\
\hline & CB-180 & NG & NG & $0.21 \pm 0.04$ & $0.61 \pm 0.10$ & $<$ d.l. \\
\hline & CB-187 & NG & NG & $0.20 \pm 0.03$ & $0.72 \pm 0.12$ & $<$ d.l. \\
\hline & CB-194 & NG & NG & $0.03 \pm 0.00$ & $0.07 \pm 0.01$ & $0.38 \pm 0.06$ \\
\hline tPCB & & 21.6 & 189 & $1.87 \pm 0.32$ & $5.64 \pm 0.96$ & $15.34 \pm 2.61$ \\
\hline \multicolumn{7}{|l|}{ DDT } \\
\hline & $\mathrm{pp}^{\prime} \mathrm{DDE}$ & 1.22 & 7.81 & $0.05 \pm 0.01$ & $0.27 \pm 0.05$ & $0.65 \pm 0.11$ \\
\hline & $\mathrm{pp}^{\prime} \mathrm{DDD}$ & 2.07 & 374 & $0.10 \pm 0.02$ & $0.28 \pm 0.05$ & $0.60 \pm 0.10$ \\
\hline & $\mathrm{pp}^{\prime} \mathrm{DDT}$ & 1.19 & 4.77 & $0.70 \pm 0.12$ & $4.39 \pm 0.75^{*}$ & $1.18 \pm 0.20$ \\
\hline tDDT & & 3.89 & 51.7 & $0.85 \pm 0.14$ & $4.94 \pm 0.84 *$ & $2.43 \pm 0.41$ \\
\hline
\end{tabular}

${ }^{\dagger}$ Threshold effects level—concentration below which contamination effects rarely occur; ${ }^{\star}$ probable effects level—concentration above which contamination effects frequently occur; * contaminant above TEL; ** contaminant above PEL; $N G$ no guideline available; <d.l. below detection limit; Ranges indicate the SE

variable and did not account for any statistically significant trends. No differences were found between replicates for all analysed elements (Mann-Whitney $U, P>0.05$ ), so data from the two replicates were grouped for further statistics. Comparatively to $T_{0}$, differences in muscle organic toxicants (Fig. 3h) were more evident for test C, especially regarding PCBs and DDTs, at $T_{14}$, even though data is incomplete due to the mortality in B and C tests, which caused the lack of minimum muscle mass for analysis. From the analysis of individual organic contaminants (Table 2) it may be inferred that the differences between sampling times regarding test $\mathrm{C}$ are caused by an increase in accumulated $\mathrm{pp}^{\prime} \mathrm{DDD}$ and $\mathrm{pp}^{\prime} \mathrm{DDE}$ (approximately twofold from $T_{0}$ to $T_{14}$ ) and tri- to pentachlorinated PCBs and a decrease in $\mathrm{pp}^{\prime} \mathrm{DDT}$ to values below the detection limit. The opposite was observed in A-tested fish at $T_{28}$, where a more than twofold increase in muscle $\mathrm{pp}^{\prime}$ DDT was observed. PAHs failed to depict any significant variation between sampling times for all tests but it was observed that fish accumulated lower molecularweight PAHs (3-ring) and not the 4- to 5-ring forms that are the most representative PAHs in the sediments, a result that is similar to studies with other marine organisms (Bihari et al. 2007). In general, bioaccumulation of both metals and organic compounds appears to reflect sediment contamination.

\section{Biomarkers}

Metallothionein induction relatively to $T_{0}$ individuals was only observed at $T_{28}$ in tests B and, especially, C, despite that the sediment $\mathrm{B}$ presented higher levels of metal contamination (Fig. 4a). No differences were found between replicates (Mann-Whitney $U, P>0.05$ ), so data from replicates were grouped for subsequent statistical analyses. Presence of a MT-compatible band in heat-treated cytosols was confirmed by SDS-PAGE (Fig. 4b). Estimated MW of S. senegalensis MT was $12 \pm 1 \mathrm{kDa}$, which is consistent with vertebrate dimeric MTs. Estimated MW of rabbit standard MTs was $13 \pm 1 \mathrm{kDa}$ for the dimeric form and $5 \pm 1 \mathrm{kDa}$ for the monomeric form. Regarding CYP1A induction, however, tests with sediments $\mathrm{A}$ and $\mathrm{B}$ were responsible for the highest induction at $T_{14}$ (relatively to $T_{0}$ ), whereas at $T_{28}$ CYP1A levels of A- and B-tested individuals reverted to a $T_{0}$-like condition and C-tested animals showed a relatively small increment in CYP1A protein content (Fig. 4c).

\section{Statistical integration of data}

Principal component analysis derived two main factors that combined explain $52.6 \%$ of all variance between tested animals. Analysis comprises all measured biological variables: bioaccumulation, biomarkers, $L_{\mathrm{s}}$ and $\mathrm{ww}_{\mathrm{t}}$ (Fig. 5). The main contributors for factor 1 , which explains the highest portion of within-individuals variance, were essentially accumulated metals, especially $\mathrm{As}, \mathrm{Cr}, \mathrm{Ni}$ and $\mathrm{Zn}$. For factor 2 the main contributors were accumulated PAHs and DDTs plus CYP1A induction, although with a very distinct opposite trend between accumulated organic compounds and cytochrome induction. Analysis did not reveal MT induction as a significant contribution for either factor.

The liver MT induction model (validation shown in Fig. 6) retrieved liver $\mathrm{Cr}$ and $\mathrm{Zn}$ to be the most significant $(P<0.05)$ metals influencing MT induction but with opposite effects, having positive and negative coefficients (linear predictors), respectively. A similar pattern was 


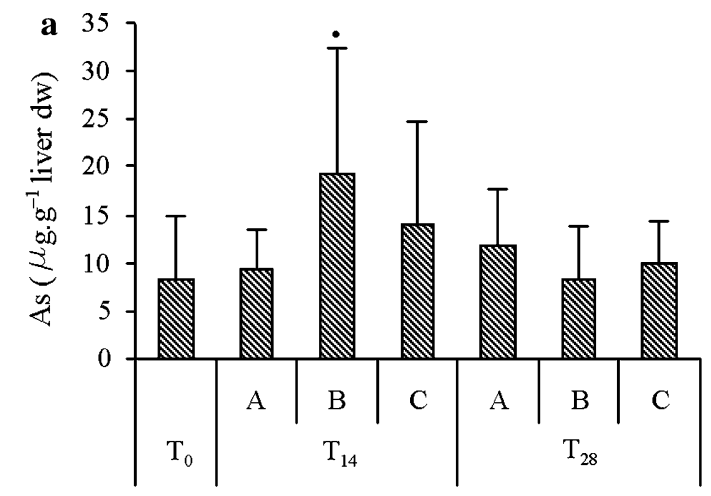

Sampling time and site

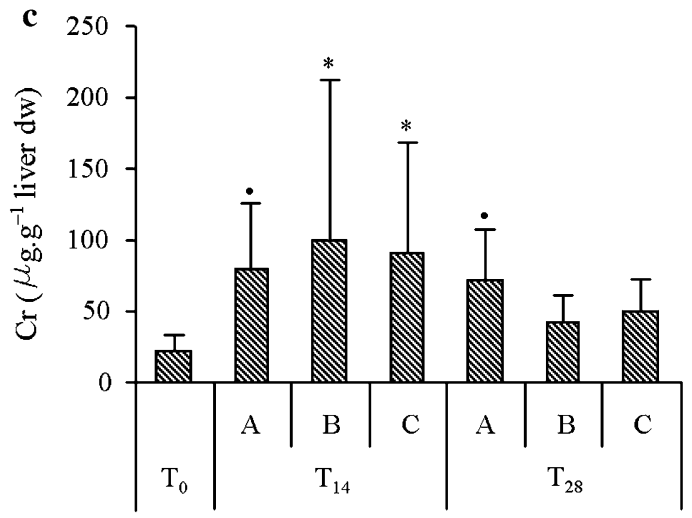

Sampling time and site

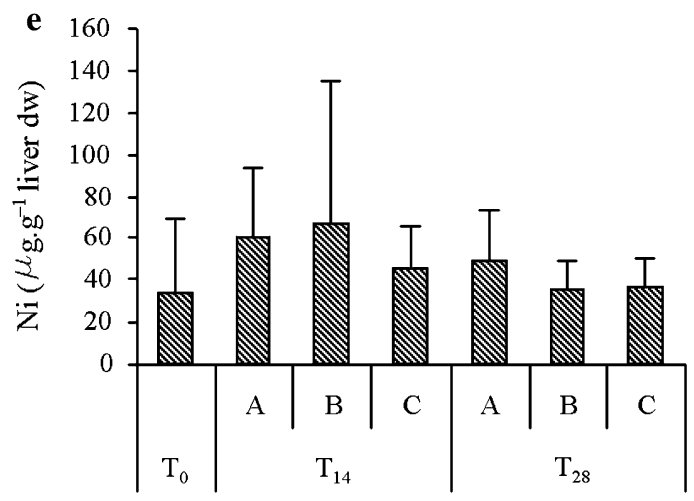

Sampling time and site

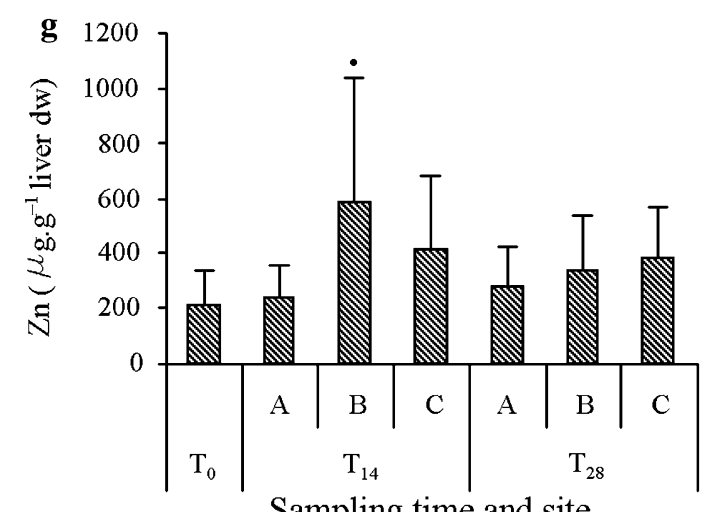

Sampling time and site

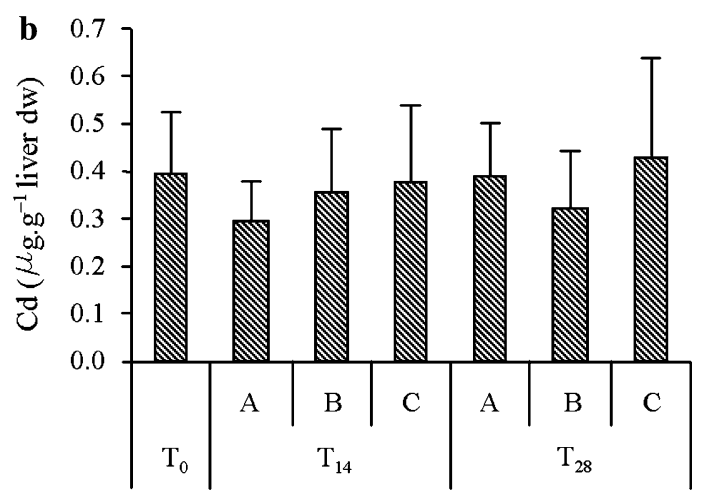

Sampling time and site

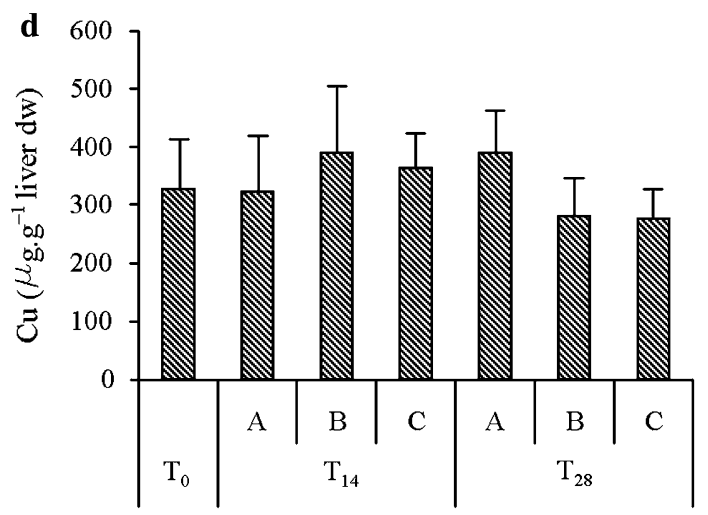

Sampling time and site

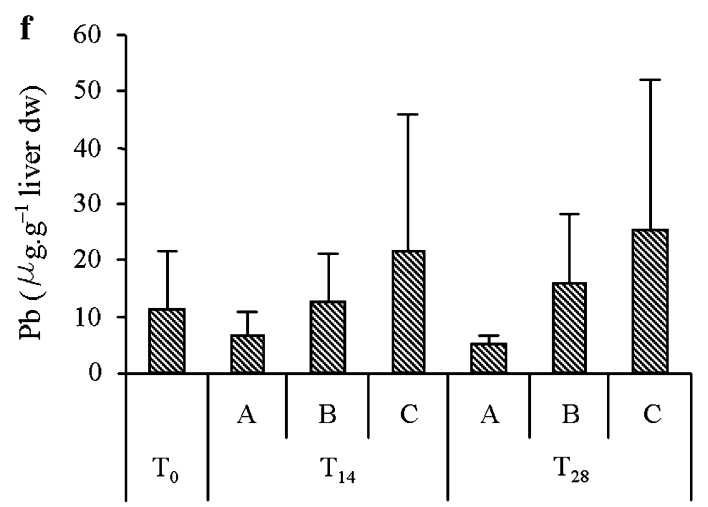

Sampling time and site

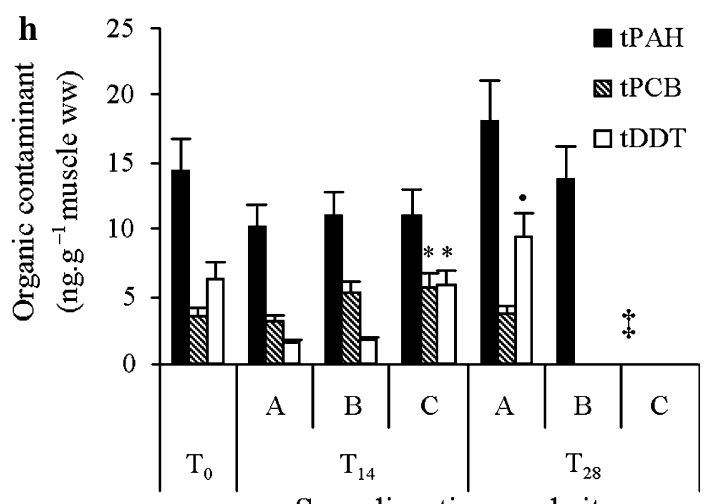

Sampling time and site 
Table 2 Bioaccumulation of individual organic contaminants in muscle of individuals exposed to sediments from sites A, B and C, for all sampling times

\begin{tabular}{|c|c|c|c|c|c|c|c|c|c|}
\hline \multicolumn{3}{|c|}{ Organic contaminant } & \multicolumn{7}{|c|}{ Contaminant concentration in muscle ( $\mathrm{ng} \mathrm{g}^{-1}$ tissue ww) } \\
\hline & & & \multirow[t]{2}{*}{$T_{0}$} & \multicolumn{2}{|l|}{ A } & \multicolumn{2}{|l|}{ B } & \multicolumn{2}{|l|}{ C } \\
\hline & & & & $T_{14}$ & $T_{28}$ & $T_{14}$ & $T_{28}$ & $T_{14}$ & $T_{28}$ \\
\hline \multirow[t]{17}{*}{ PAH } & 3-Ring & Acenaphthylene & $0.91 \pm 0.15$ & $0.57 \pm 0.10$ & $0.79 \pm 0.13$ & $0.52 \pm 0.09$ & $0.80 \pm 0.14$ & $0.60 \pm 0.10$ & - \\
\hline & & Acenaphthene & $1.82 \pm 0.31$ & $1.48 \pm 0.25$ & $1.80 \pm 0.31$ & $1.40 \pm 0.24$ & $1.70 \pm 0.29$ & $1.71 \pm 0.29$ & - \\
\hline & & Fluorene & $1.67 \pm 0.28$ & $1.06 \pm 0.18$ & $1.89 \pm 0.32$ & $1.18 \pm 0.20$ & $1.71 \pm 0.29$ & $1.23 \pm 0.21$ & - \\
\hline & & Phenanthrene & $3.94 \pm 0.67$ & $2.80 \pm 0.48$ & $4.21 \pm 0.71$ & $2.56 \pm 0.44$ & $3.40 \pm 0.58$ & $2.37 \pm 0.40$ & - \\
\hline & & Anthracene & $0.27 \pm 0.05$ & $0.17 \pm 0.03$ & $0.33 \pm 0.06$ & $0.25 \pm 0.04$ & $0.33 \pm 0.06$ & $0.25 \pm 0.04$ & - \\
\hline & 4-Ring & Fluoranthene & $1.66 \pm 0.28$ & $1.11 \pm 0.19$ & $1.68 \pm 0.29$ & $1.48 \pm 0.25$ & $1.86 \pm 0.32$ & $1.44 \pm 0.24$ & - \\
\hline & & Pyrene & $1.58 \pm 0.27$ & $1.09 \pm 0.19$ & $1.54 \pm 0.26$ & $1.32 \pm 0.22$ & $1.66 \pm 0.28$ & $1.40 \pm 0.24$ & - \\
\hline & & Benz(a)anthracene & $0.19 \pm 0.03$ & $0.12 \pm 0.02$ & $0.21 \pm 0.04$ & $0.15 \pm 0.03$ & $0.15 \pm 0.02$ & $0.11 \pm 0.02$ & - \\
\hline & & Chrysene (218-01-9) & $0.65 \pm 0.11$ & $0.39 \pm 0.07$ & $3.88 \pm 0.66$ & $0.44 \pm 0.07$ & $0.51 \pm 0.09$ & $0.37 \pm 0.06$ & - \\
\hline & 5-Ring & Benzo(b)fluoranthrene & $0.60 \pm 0.10$ & $0.44 \pm 0.07$ & $0.56 \pm 0.10$ & $0.52 \pm 0.09$ & $0.62 \pm 0.11$ & $0.47 \pm 0.08$ & - \\
\hline & & Benzo(k)fluoranthrene & $0.29 \pm 0.05$ & $0.19 \pm 0.03$ & $0.29 \pm 0.05$ & $0.25 \pm 0.04$ & $0.35 \pm 0.06$ & $0.23 \pm 0.04$ & - \\
\hline & & Benzo(e)pyrene & $0.22 \pm 0.04$ & $0.16 \pm 0.03$ & $0.21 \pm 0.04$ & $0.19 \pm 0.03$ & $0.23 \pm 0.04$ & $0.19 \pm 0.03$ & - \\
\hline & & Benzo(a)pyrene & $0.26 \pm 0.04$ & $0.27 \pm 0.05$ & $0.38 \pm 0.06$ & $0.29 \pm 0.05$ & $0.33 \pm 0.06$ & $0.16 \pm 0.03$ & - \\
\hline & & Perylene & $0.27 \pm 0.05$ & $0.29 \pm 0.05$ & $0.30 \pm 0.05$ & $0.37 \pm 0.06$ & $0.22 \pm 0.04$ & $0.58 \pm 0.10$ & - \\
\hline & & Dibenzo(a,h)anthracene & $<$ d.1. & $<$ d.1. & $<$ d.1. & $<$ d.1. & $0.00 \pm 0.00$ & $<$ d.l. & - \\
\hline & 6-Ring & Indeno(1,2,3-cd)pyrene & $<$ d.1. & $<$ d.l. & $<$ d.l. & $<$ d.l. & $0.00 \pm 0.00$ & $<$ d.l. & - \\
\hline & & Benzo(g,h,i)perylene & $<$ d.1. & $<$ d.l. & $<$ d.l. & $<$ d.l. & $0.00 \pm 0.00$ & $<$ d.l. & - \\
\hline \multirow[t]{18}{*}{ PCB } & Trichlorinated & CB-18 & $0.01 \pm 0.00$ & $0.02 \pm 0.00$ & $0.04 \pm 0.01$ & $0.16 \pm 0.03$ & - & $0.12 \pm 0.02$ & - \\
\hline & & CB-26 & $<$ d.1. & $0.02 \pm 0.00$ & $0.03 \pm 0.01$ & $0.02 \pm 0.00$ & - & $0.32 \pm 0.05$ & - \\
\hline & & CB-31 & $0.21 \pm 0.04$ & $0.43 \pm 0.07$ & $0.28 \pm 0.05$ & $1.64 \pm 0.28$ & - & $0.42 \pm 0.07$ & - \\
\hline & Tetrachlorinated & CB-44 & $0.05 \pm 0.01$ & $0.04 \pm 0.01$ & $0.07 \pm 0.01$ & $0.12 \pm 0.02$ & - & $0.18 \pm 0.03$ & - \\
\hline & & CB-49 & $0.05 \pm 0.01$ & $0.04 \pm 0.01$ & $0.08 \pm 0.01$ & $0.06 \pm 0.01$ & - & $0.11 \pm 0.02$ & - \\
\hline & & CB-52 & $0.07 \pm 0.01$ & $0.54 \pm 0.09$ & $0.09 \pm 0.02$ & $0.26 \pm 0.04$ & - & $0.24 \pm 0.04$ & - \\
\hline & Pentachlorinated & CB-101 & $0.22 \pm 0.04$ & $0.14 \pm 0.02$ & $0.19 \pm 0.03$ & $0.25 \pm 0.04$ & - & $0.53 \pm 0.09$ & - \\
\hline & & CB-105 & $0.11 \pm 0.02$ & $0.04 \pm 0.01$ & $0.19 \pm 0.03$ & $0.09 \pm 0.01$ & - & $0.14 \pm 0.02$ & - \\
\hline & & CB-118 & $0.02 \pm 0.00$ & $0.26 \pm 0.04$ & $0.03 \pm 0.01$ & $0.41 \pm 0.07$ & - & $0.70 \pm 0.12$ & - \\
\hline & Hexachlorinated & CB-128 & $0.07 \pm 0.01$ & $0.36 \pm 0.06$ & $0.05 \pm 0.01$ & $0.07 \pm 0.01$ & - & $0.07 \pm 0.01$ & - \\
\hline & & CB-138 & $0.64 \pm 0.11$ & $0.31 \pm 0.05$ & $0.59 \pm 0.10$ & $0.53 \pm 0.09$ & - & $0.44 \pm 0.07$ & - \\
\hline & & CB-149 & $0.68 \pm 0.12$ & $0.16 \pm 0.03$ & $1.58 \pm 0.27$ & $0.29 \pm 0.05$ & - & $0.49 \pm 0.08$ & - \\
\hline & & CB-151 & $0.10 \pm 0.02$ & $0.06 \pm 0.01$ & $0.07 \pm 0.01$ & $0.13 \pm 0.02$ & - & $0.22 \pm 0.04$ & - \\
\hline & & CB-153 & $0.64 \pm 0.11$ & $0.34 \pm 0.06$ & $<$ d.l. & $0.61 \pm 0.10$ & - & $1.02 \pm 0.17$ & - \\
\hline & Heptachlorinated & CB-170 & $0.05 \pm 0.01$ & $0.02 \pm 0.00$ & $0.02 \pm 0.00$ & $0.07 \pm 0.01$ & - & $<$ d.l. & - \\
\hline & & CB-180 & $0.21 \pm 0.04$ & $0.11 \pm 0.02$ & $0.13 \pm 0.02$ & $0.21 \pm 0.04$ & - & $0.24 \pm 0.04$ & - \\
\hline & & CB187 & $0.32 \pm 0.05$ & $0.18 \pm 0.03$ & $0.21 \pm 0.04$ & $0.33 \pm 0.06$ & - & $0.51 \pm 0.09$ & - \\
\hline & & CB-194 & $<$ d.l. & $<$ d.l. & $0.00 \pm 0.00$ & $<$ d.l. & - & $<$ d.l. & - \\
\hline \multirow[t]{3}{*}{ DDT } & & $\mathrm{pp}^{\prime} \mathrm{DDE}$ & $1.31 \pm 0.22$ & $0.77 \pm 0.13$ & $0.90 \pm 0.15$ & $1.36 \pm 0.23$ & - & $2.58 \pm 0.44$ & - \\
\hline & & $\mathrm{pp}^{\prime} \mathrm{DDD}$ & $1.33 \pm 0.23$ & $0.43 \pm 0.07$ & $0.65 \pm 0.11$ & $0.29 \pm 0.05$ & - & $3.27 \pm 0.56$ & - \\
\hline & & $\mathrm{pp}^{\prime} \mathrm{DDT}$ & $3.75 \pm 0.64$ & $0.28 \pm 0.05$ & $7.98 \pm 1.36$ & $0.08 \pm 0.01$ & - & $<\mathrm{d} .1$ & - \\
\hline
\end{tabular}

$<$ d.l. Below detection limit; - unavailable data. Ranges indicate the SE

4 Fig. 3 Bioaccumulation results. * and $\bullet$ represent significant differences from $T_{0}$ individuals, $P<0.05$ and $P<0.10$, respectively. a-g Average concentration of metals in liver (Mann-Whitney $U$, error bars represent $95 \%$ confidence intervals, $N=12$ fish per treatment and sampling time). $\mathbf{h}$ Concentration of major organic contaminant classes in pooled muscle samples (Chi-square Expected $\times$ Observed test between individual contaminants, error bars indicate the SE). $\$$ indicates missing data due to mortality 

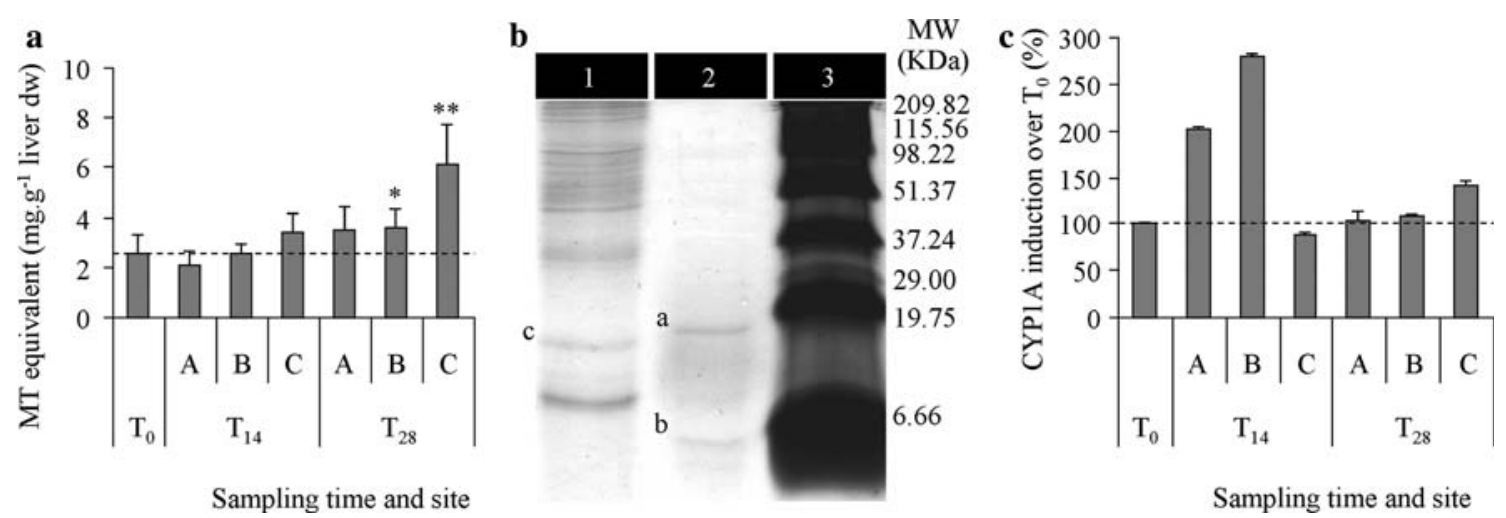

Fig. 4 Results from biomarker analyses. a Average MT concentration in the liver of exposed individuals $(N=12$ fish per treatment and sampling time). $*$ and $* *$ represent significant differences from $T_{0}$ (dashed line) $P \leq 0.1$ and $P<0.01$, respectively (Student's $t$-test on GLM coefficients). Error bars represent $95 \%$ confidence intervals. b SDS-PAGE confirmation of the presence of a MT-compatible band in

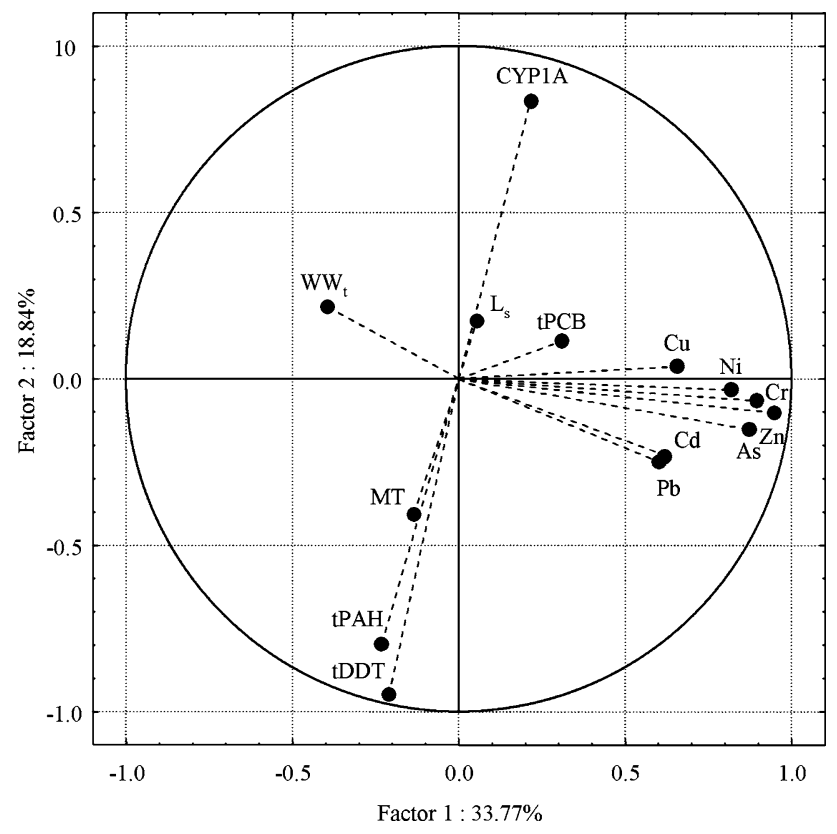

Fig. 5 PCA scatterplot for all biological variables (Factor 1 Eigenvalue $=4.73$, Factor 2 Eigenvalue $=2.64$ )

detected regarding accumulated tPAHs (although less significantly) and tDDTs in muscle (Table 3). The effect of an interaction between $\mathrm{ww}_{\mathrm{t}}$ and $L_{\mathrm{s}}\left(\mathrm{ww}_{\mathrm{t}}: L_{\mathrm{s}}\right)$. was also found to be close to the level of significance but $L_{\mathrm{s}}$ as an isolated variable did not significantly reduce model deviance whereas $\mathrm{ww}_{\mathrm{t}}$ only marginally did so.

\section{Discussion and conclusions}

Sediment metals were found to be in general accordance with contamination levels previously assessed in the
S. senegalensis liver. Lanes: 1-Heat-treated cytosol from a $T_{28}$-collected individual (test C), 2-rabbit MT standard, 3-Broadrange protein ladder. $\mathbf{a}, \mathbf{b}$ Dimeric and monomeric forms of rabbit MT, respectively, c dimeric form of $S$. senegalensis MT. MW: protein molecular weight. c CYP1A induction in pooled liver samples of exposed individuals over $T_{0}$ (dashed line). Error bars represent the SE

estuary (Caeiro et al. 2005), although a moderate decline in metals can be noticed, from previous to current data, and organic contamination analysis reveals a very pronounced decrease in tPAHs for all stations (up to tenfold), the inverse being observed for tPCBs (Neuparth et al. 2005) and tDDTs in sediment B (Caeiro et al. this issue). Globally, the observed sediment contamination profiles reflect the expected distribution and sources of toxicants in the area.

Bioavailability of sediment contaminants was most probably enhanced by sediment disaggregation and resuspension caused by sediment collection, assay set-up and fish activity. This may explain why bioaccumulation of metals was considerably higher at the assays mid-term rather than at its terminus since a decrease in suspended matter was observed during the experiment. Metals may have been released from suspended matter and therefore made available to be absorbed through gills and other epithelia in contact with water, accumulated in the liver and then gradually eliminated when uptake decreased. Bioaccumulation of organic contaminants does not so evidently reflect this pattern but it is clearly related to sediment contamination, especially regarding PCBs and DDT metabolites ( $\mathrm{pp}^{\prime} \mathrm{DDD}$ and $\left.\mathrm{pp}^{\prime} \mathrm{DDE}\right)$ in sediment C-tested fish (but not $\mathrm{pp}^{\prime} \mathrm{DDT}$ itself, showing that active metabolism of the toxicant occurred). Regarding PAHs, although the best represented class of organic contaminants in the sediments, no obvious bioaccumulation occurred. Flatfish, however, have already been described to rapidly catabolise PAHs (Varanasi and Gmur 1981).

Even at low concentrations, metals in sediment $\mathrm{C}$ accumulated in the livers of tested fish. This result confirms that contaminant bioavailability (metallic and organic) was further enhanced in tests with this sediment. Together with high FF and TOM, which may have acted as a trap for 
Fig. 6 Validation of GLM assumptions for the MT induction model. a Random scatter of Pearson residuals, b normality of residuals, $\mathbf{c}$ and d Cook's statistic $h$ results, showing that only a very reduced number of cases may cause estimate biasing
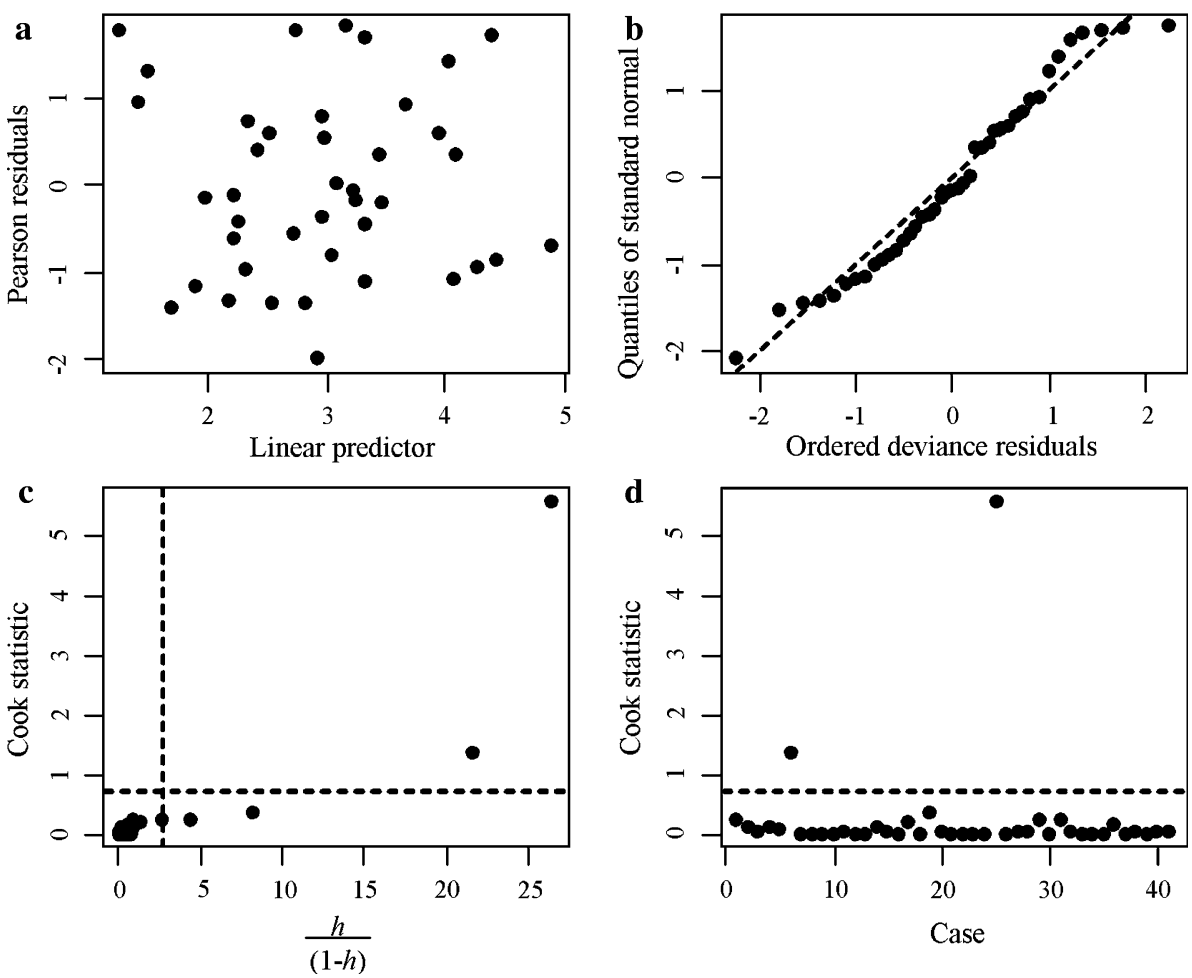

Table 3 Results from GLM ANOVA based on analysis of deviance of the MT induction model

\begin{tabular}{lcl}
\hline Model component & $\chi^{2}$ test $P$ & Coefficient type \\
\hline Cr in liver & $<0.05$ & Negative \\
Zn in liver & $<0.05$ & Positive \\
tPAH in muscle & 0.06 & Negative \\
tDDT in muscle & $<0.05$ & Positive \\
$\mathrm{ww}_{\mathrm{t}}$ & 0.09 & Positive \\
$\mathrm{ww}_{\mathrm{t}}: L_{\mathrm{s}}$ & 0.08 & Negative \\
\hline
\end{tabular}

Only the most significant model components (explanatory variables) are presented

contaminants (Caccia et al. 2003), low Eh mostly likely increased bioavailability upon resuspension (Caetano et al. 2003; Eggleton and Thomas 2004), thus contributing for the higher toxicity (chronic and acute) of sediment $\mathrm{C}$. The combination of FF and TOM with resuspension during the assays with natural sediments as already been detected as a probable cause of metal release from sediments, consequently enhancing metal uptake and MT response (Costa et al. 2008b). Atkinson et al. (2007) demonstrated that physical mixing and bioturbation were more responsible for the enhancement of metal availability than changes in $\mathrm{pH}, \mathrm{DO}_{2}$, or even salinity, and were furthermore responsible for maintaining high bioavailability. Other research shows that organic contaminants have more complex desorption processes (e.g. due to hydrophobicity), still enhanced by turbation (Vale et al. 1998; Hellou et al.
2005). This information supports the presented data and confirms the importance of assay conditions during sediment tests.

Our findings demonstrate that MT induction cannot be exclusively explained by metals in the sediment or in the organism. MT induction is known to be modulated by both metals and organic contaminants but previous findings are sometimes contradictory. Simultaneous exposure to $\mathrm{Cu}$ and benzo[a]pyrene $(\mathrm{B}[\mathrm{a}] \mathrm{P})$, was found to greatly increase MT induction in fish liver even when exposure to the individual contaminants reduced MT expression (Roméo et al. 1997). On the other hand, MT induction caused by a mixture of metals $(\mathrm{Cd}, \mathrm{Cu}, \mathrm{Pb}$ and $\mathrm{Zn})$ has been found to be suppressed by PAHs (Risso-de Faverney et al. 2000). MT induction may also be influenced by various stress-inducing conditions followed by exposure to strong MT-inducing metals. Sampaio et al. (2008) found MT induction to be modulated in fish by simultaneous exposure to moderate levels of $\mathrm{Cu}$ and hypoxia (but not significantly by each effect alone), accompanied by an enhancement in superoxide dismutase (SOD) activity, which should reflect an increase in ROS. In fact, the importance of MTs to scavenge oxidative radicals has already been demonstrated in fish and other aquatic organisms, appearing to be negatively correlated to the amount of metal thiolates formed, presumably due to the availability of MT thiols to bind to ROS or ROS-related compounds (Buico et al. 2008). It is thus possible that oxidative stress resulting from the catabolism of organic compounds, and not metal in liver 
alone, was responsible for the very significant increase in liver MT observed in C-tested individuals.

According to our findings, accumulated metals play different roles in MT induction: while Cd does not appear to be linked to MT induction (likely due to its low levels in tested sediments), $\mathrm{Cr}$ and $\mathrm{Zn}$ (well represented in sediments, especially in B) have been found very significantly related to MT induction but with opposite effects. Although $\mathrm{Cr}$ alone is capable to induce MT synthesis in fish liver (Roberts and Oris 2004) it is known to have an antagonist effect in MT induction in the presence of high MT-affinity metals like $\mathrm{Cd}$ and $\mathrm{Zn}$ (Majumder et al. 2003). MT induction in fish is also known to be mediated by other variables such as age, size and sex (Hamza-Chaffai et al. 1995). In the present work, the age factor can be excluded from analysis since animals belong to the same cohort (as well as sex, due to immatureness of individuals). Our results suggest that fish biomass may have incremented MT synthesis. On the other hand, a negative effect caused by the interaction between $L_{\mathrm{s}}$ and $\mathrm{ww}_{\mathrm{t}}$ suggests that MT down-regulation may occur when the expected linear relationship between body length and size is not met. In fact, only a moderate correlation between $L_{\mathrm{s}}$ and $\mathrm{ww}_{\mathrm{t}}$ was observed (Spearman's $R=0.69, P<0.01$ ). This data confirms the relevance of intraspecific variability in MT response.

Some authors have argued that caution is mandatory when MT induction is considered as a biomarker of metal contamination in sediment biomonitoring, especially when low levels of strong inducers (like $\mathrm{Cd}$ ) are involved (Mouneyrac et al. 2002). This statement is validated when our results are compared to those obtained by JiménezTenorio et al. (2007), who found MT induction in S. senegalensis liver perfectly linked to sediment metals but with these (especially $\mathrm{Cd}$ and $\mathrm{Zn}$ ) having been found to be in a tenfold order of magnitude relatively to concentrations in the sediments here described, with organic contaminants being found only in trace concentrations. The present results show that MT induction, although little related to metal exposure, can be successfully employed even in tests with moderately metal-contaminated sediments at least as a stress response, a role for fish MT that has already been proposed by other authors, e.g. Viarengo et al. (1999)

It is long known that metals and metalloids are CYP1A suppressors, even in presence of known strong CYP1A inducers (Brüschweiler et al. 1996; Vakharia et al. 2001; Spink et al. 2002). Although many details on the mechanism are still lacking, it is generally recognized that one of the most important causes of CYP1A suppression is a metal- or metalloid-caused induction of the hemeoxygenase enzyme, enhancing degradation of heme groups and therefore reducing its availability as the prosthetic group of CYP1A (Spink et al. 2002). This inhibitor effect may actually decrease short-term PAH toxicity since PAH degradation involves formation of the highly toxic activated PAH forms (e.g. PAH o-quinones and diol epoxides) and ROS as by-products of cytochrome activity (e.g. Flowers-Geary et al. 1996), thus contributing to explain why sediment B was responsible for much reduced lethality when compared to C. The absence of CYP1A induction in sediment C-tested fish sampled at $T_{14}$ is only partially explained by cytochrome suppression caused by metals but still, the opposite trend between accumulated PAHs (and DDTs) and CYP1A induction confirms the cytochrome's role in the metabolism of organic contaminants. It should not be discarded, nevertheless, that a rapid organic contaminant uptake and catabolism at the beginning of the assay with sediment $\mathrm{C}$ may have also led to depletion in accumulated compounds and consequently contributed to a reduction in CYP1A induction from $T_{0}$ to $T_{14}$ and an increase in activated PAHs and ROS.

Down-regulation of CYP1A has already been documented as a direct result of ROS activity (Morel and Barouki 1998) and exposure to PCBs (Celander et al. 1996). Although not yet well understood, it is known that tetra- and penta-chlorinated PCBs may induce CYP1A protein synthesis but suppress its activity in fish liver in a dose-dependent manner, causing a significant increase in ROS (Gooch et al. 1989; Schlezinger and Stegeman 2001). Since tetra- and penta-chlorinated PCBs are relatively well represented in sediment $C$ (approximately threefold more contaminated with these PCBs than B and almost tenfold than A) formation of ROS and PCB bioaccumulation in livers may have resulted in a diminished CYP1A induction.

The results show that sediment parameters may influence toxicity by determining bioavailability. Furthermore, the laboratorial assays were proven to enhance bioavailability by a conjunction of sediment physico-chemical characteristics and resuspension, allowing an estimate of increasing toxicity to biota when sediment-disturbing events such as dredgings, heavy seasonal runoffs or storms affect contaminated estuarine areas. The present work demonstrated that toxicity of sediment contaminants to young benthic fish is influenced by synergistic and antagonistic processes that result from exposure to a mixture of xenobiotics. The biomarkers and bioaccumulation analyses were successfully integrated and allowed assessment of cause-effect relationships between contaminants and toxicity and, most importantly, provided a valuable insight on what happens in the fuzzy area where actual toxicity results from the superimposition of contaminants in complex matrices like estuarine sediments.

Acknowledgments This work was approved by the Portuguese Science and Technology Foundation (FCT) and POCTI (Programa Operacional Ciência, Tecnologia e Inovação, research project ref. 
POCTI/AMB 57281/104) and financed by FEDER (European Fund for Regional Development). P. M. Costa is supported by a FCT PhD grant (SFRH/BD/28465/2006). The authors would also like to thank APSS (Administração dos Portos de Setúbal e Sesimbra, SA) and RNES (Reserva Natural do Estuário do Sado) for the logistic support and P. Pousão (Estação Piloto de Piscicultura, INRB/IPIMAR-Cripsul) for supplying the fish used in the present work.

\section{References}

Atkinson CA, Jolley DF, Simpson SL (2007) Effect of overlying water $\mathrm{pH}$, dissolved oxygen, salinity and sediment disturbances on metal release and sequestration from metal contaminated marine sediments. Chemosphere 69:1428-1437

Bihari N, Fafanđel M, Piškur V (2007) Polycyclic aromatic hydrocarbons and ecotoxicological characterization of seawater, sediment, and mussel Mytilus galloprovincialis from the gulf of Rijeka, the Adriatic Sea, Croatia. Arch Environ Con Tox 52:379-387

Brüschweiler BJ, Würgler FE, Fent K (1996) Inhibitory effects of heavy metals on cytochrome P4501A induction in permanent fish hepatoma cells. Arch Environ Con Tox 31:475-482

Buico A, Cassino C, Dondero F, Vergani L, Osella D (2008) Radical scavenging metallothionein isoforms: an ESR study. J Inorg Biochem 102:921-927

Caccia VG, Sillero FJ, Palanques A (2003) The distribution of trace metals in Florida Bay sediments. Mar Pollut Bull 46:1420-1433

Caeiro S, Costa MH, Ramos TB, Fernandes F, Silveira N, Coimbra A, Medeiros G, Painho M (2005) Assessing heavy metal contamination in Sado Estuary sediment: an index analysis approach. Ecol Indic 5:151-169

Caetano M, Madureira MJ, Vale C (2003) Metal contaminated remobilisation during resuspension of anoxic contaminated sediment: short-term laboratory study. Water Air Soil Pollut 143:23-40

Caetano M, Fonseca N, Cesário R, Vale C (2007) Mobility of Pb in salt marshes recorded by total content and stable isotopic signature. Sci Total Environ 380:84-92

Candiano G, Bruschi M, Musante L, Santucci L, Ghiggeri GM, Carnemolla M, Orecchia P, Zardi L, Righetti PG (2004) Blue silver: a very sensitive colloidal Coomassie G-250 staining for proteome analysis. Electrophoresis 25:1327-1333

Celander M, Stegeman JJ, Förlin L (1996) CYP1A1-, CYP2B and CYP3A-like proteins in rainbow trout (Oncorhynchus mykiss) liver: CYP1A-specific down-regulation after prolonged exposure to PCB. Mar Environ Res 42:283-286

Chapman PM (1990) The sediment quality triad approach to determining pollution-induced degradation. Sci Total Environ 97-98:815-825

Clesceri LS, Greenberg AE, Eaton AD (1999) Standard methods for examination of water \& wastewater, 20th edn. American Public Health Association, Baltimore

Costa PM, Costa MH (2008) Biochemical and histopathological endpoints of in vivo cadmium toxicity in Sparus aurata. Cienc Mar 34:349-361

Costa PM, Lobo J, Caeiro S, Martins M, Ferreira AM, Caetano M, Vale C, DelValls TA, Costa MH (2008a) Genotoxic damage in Solea senegalensis exposed to sediments from the Sado Estuary (Portugal): effects of metallic and organic contaminants. Mutat Res 654:29-37

Costa PM, Repolho T, Caeiro S, Diniz ME, Moura I, Costa MH (2008b) Modelling metallothionein induction in the liver of Sparus aurata exposed to metal-contaminated estuarine sediments. Ecotoxicol Environ Saf 71:117-124
Eggleton J, Thomas KV (2004) A review of factors affecting the release and bioavailability of contaminants during sediment disturbance events. Environ Int 30:973-980

Ferreira AM, Martins M, Vale C (2003) Influence of diffuse sources on levels and distribution of polychlorinated biphenyls in the Guadiana River estuary, Portugal. Mar Chem 89:175-184

Flowers-Geary L, Bleczinski W, Harvey RG, Penning TM (1996) Cytotoxicity and mutagenicity of polycyclic aromatic hydrocarbon $o$-quinones produced by dihydrodiol dehydrogenase. Chem Biol Interact 99:66-72

Gooch JW, Elskus AA, Kloepper-Sams PJ, Hahn ME, Stegeman JJ (1989) Effects of ortho and non-ortho substituted polychlorinated biphenyl congeners on the hepatic monooxygenase system in scup (Stenotomus chrysops). Toxicol Appl Pharmacol 98: $422-433$

Hamza-Chaffai A, Cosson RP, Amiard-Triquet C, El Abed A (1995) Physico-chemical forms of storage of metals $(\mathrm{Cd}, \mathrm{Cu}$ and $\mathrm{Zn})$ and metallothionein-like proteins in gills and liver of marine fish from the Tunisian coast: ecotoxicological consequences. Comp Biochem Physiol C 111:329-341

Hellou J, Steller S, Leonard J, Langille MA, Trembley D (2005) Partitioning of polycyclic aromatic hydrocarbons between water and particles compared to bioaccumulation in mussels: a harbour case. Mar Environ Res 59:101-117

Ihaka R, Gentleman R (1996) R: a language for data analysis and graphics. J Comput Graph Stat 5:299-314

Jiménez-Tenorio N, Morales-Caselles C, Kalman J, Salamanca MJ, de Canales MLG, Sarasquete C, DelValls TA (2007) Determining sediment quality for regulatory purposes using fish chronic bioassays. Environ Int 33:474-480

Jönsson ME, Brunström B, Brandt I (2009) The zebrafish gill model: Induction of CYP1A, EROD and PAH adduct formation. Aquat Toxicol 91:62-70

Macdonald DD, Carr S, Calder F, Long E, Ingersoll C (1996) Development and evaluation of sediment quality guidelines for Florida coastal waters. Ecotoxicology 5:253-278

Majumder S, Ghoshal K, Summers D, Bai S, Datta J, Jacob ST (2003) Chromium (IV) down-regulates heavy-metal induced metallothionein gene transcription by modifying transactivation potential of the key transcription factor, metal-responsive transcription factor 1. J Biol Chem 278:26216-26226

Martins M, Ferreira AM, Vale C (2008) The influence of Sarcocornia fruticosa on retention of PAHs in salt marshes sediments (Sado estuary, Portugal). Chemosphere 71:1599-1606

McCullagh P, Nelder JA (1989) Generalized linear models, 2nd edn. Chapman \& Hall, London

Morel Y, Barouki R (1998) Down-regulation of cytochrome P450 1A1 gene promoter by oxidative stress. J Biol Chem 41:2696926976

Mouneyrac C, Amiard JC, Amiard-Triquet C, Cottier A, Rainbow PS, Smith BD (2002) Partitioning of accumulated trace metals in the talitrid amphipod crustacean Orchestia gammarellus: a cautionary tale on the use of metallothionein-like proteins as biomarkers. Aquat Toxicol 57:225-242

Neuparth T, Correia AD, Costa FO, Lima G, Costa MH (2005) Multilevel assessment of chronic toxicity of estuarine sediments with the amphipod Gammarus locusta: I. Biochemical endpoints. Mar Environ Res 60:69-91

Nilsen BM, Berg K, Goksøir A (1998) Induction of cytochrome P450 1A (CYP1A) in fish-a biomarker for environmental pollution. In: Phillips IR, Shephard EA (eds) Methods in molecular biology: cytochome P450 protocols (107). Humana Press Inc., Totowa, pp 423-438

Risso-de Faverney C, Lafaurie M, Girard J-P, Rahmani R (2000) Effects of heavy metals and 3-methylcholanthrene on expression and induction of CYP1A1 and metallothionein levels in trout 
(Oncorhynchus mykiss) hepatocyte cultures. Environ Toxicol Chem 19:2239-2248

Roberts AP, Oris JT (2004) Multiple biomarker responses in rainbow trout during exposure to hexavalent chromium. Comp Biochem Physiol C 138:221-228

Roméo M, Cosson RP, Gnassia-Barelli M, Risso C, Stien X, Lafaurie M (1997) Metallothionein determination in the liver of the sea bass Dicentrarchus labrax treated with copper and B(a)P. Mar Environ Res 44:275-284

Romero-Isart N, Vašak M (2002) Advances in the structure and chemistry of metallothioneins. J Inorg Biochem 88:388-396

Sampaio FG, Boijink CL, Oba ET, dos Santos LRB, Kalinin AL, Rantin FT (2008) Antioxidant defenses and biochemical changes in pacu (Piaractus mesopotamicus) in response to single and combined copper and hypoxia exposure. Comp Biochem Physiol C 147:43-51

Schlezinger JJ, Stegeman JJ (2001) Induction and suppression of cytochrome P450 1A by 3, 3', 4, 4', 5-pentachlorobyphenyll and its relationship to oxidative stress in the marine fish scup (Stenotomus chrysops). Aquat Toxicol 52:101-115

Sheskin FJ (2000) Handbook of parametric and nonparametric statistical procedures, 2nd edn. Chapman \& Hall, Boca Raton
Spink DC, Katz BH, Hussain MM, Spink BC, Wu S, Liu N, Pause R, Kaminsky RP (2002) Induction of CYP1A1 and CYP1B1 in T-47D human breast cancer cells by benzo[a]pyrene is diminished by arsenite. Drug Metab Dispos 30:262-269

Vakharia DD, Liu N, Pause R, Fasco M, Bessette E, Zhang Q-Y, Kamisnky LS (2001) Polycyclic aromatic hydrocarbon/metal mixtures: effect on PAH induction of CYP1A1 human HEPG2 cells. Drug Metab Dispos 29:999-1006

Vale C, Ferreira AM, Caetano M, Pereira E, Madureira MJ, Ramalhosa E (1998) Mobility of contaminants in relation to dredging operations in a mesotidal estuary (Tagus estuary, Portugal). Water Sci Technol 37:25-31

Varanasi U, Gmur DJ (1981) Hydrocarbons and metabolites in English sole (Parophrys vetulus) exposed simultaneously to $\left[{ }^{3} \mathrm{H}\right]$ benzo[a]pyrene and $\left[{ }^{14} \mathrm{C}\right]$ naphthalene in oil-contaminated sediment. Aquat Toxicol 1:49-67

Viarengo A, Burlando B, Dondero F, Marro A, Fabbri R (1999) Metallothionein as a tool in biomonitoring programmes. Biomarkers 4:455-466 